\title{
Konjenital lober amfizem: olgu sunumu
}

\section{Congenital lobar emphysema: a case report}

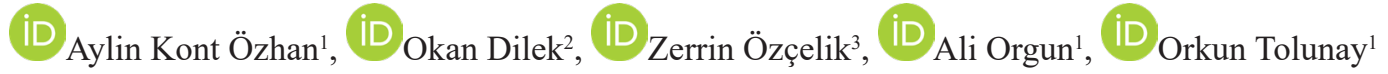

${ }^{1}$ Adana Şehir Eğitim ve Araştırma Hastanesi, Çocuk Sağlığı ve Hastalıkları Kliniği, Adana

${ }^{2}$ Adana Şehir Eğitim ve Araştırma Hastanesi, Radyoloji Kliniği, Adana

${ }^{3}$ Adana Şehir Eğitim ve Araştırma Hastanesi, Çocuk Cerrahi Servisi, Adana

Öz

Özet: Konjenital lober amfizem, alt solunum yollarında hiperinflasyon ile karakterize nadir rastlanan akciğerin doğumsal bir anomalisidir. Konjenital lober amfizemli hastalarda klinik seyir, hastalığın ortaya çıktı̆̆ı yaşa, etkilenen loba veya normal lobların baskılanmasına bağlı olarak değişebilir. Tanısı klinik ve görüntüleme yöntemleri ile birlikte konulur. Semptomları hafif olan olgular konservatif tedavi ile izlenirken, ağır solunum semptomu olan olguların lobektomi ile tedavisi iyi sonuçlar vermektedir. Konjenital lober amfizem, nadir görülen bir akciğer anomalisi olmasına rağmen, nedeni bilinmeyen solunum sıkıntısı olan hastalarda ayırıcı tanıda göz önünde bulundurulması gereken bir hastalıktır. Bu yazıda erken dönemde konjenial lober amfizem tanısı konulan, hafif semptomları olması nedeniyle de konservatif tedavi yöntemleri ile izlenilen 4 aylık kız hasta sunulmaktadır.

Anahtar Kelimeler: çocuk, konjenital lober amfizem, konservatif tedavi

Abstract

Abstract: Congenital lobar emphysema is a rare congenital anomaly of the lung characterized by hyperinflation of the lower respiratory tract. In patients with congenital lobar emphysema, the clinical course may vary depending on the age at which the disease occurs, suppression of the affected lobe or normal lobes. Diagnosis is made together with clinical and imaging methods. While the patients with mild symptoms are followed with conservative treatment, the treatment of patients with severe respiratory symptoms with lobectomy gives good results. Although congenital lobar emphysema is a rare lung anomaly, it should be considered in the differential diagnosis in patients with unresolved respiratory distress. In this article, we present a 4-month-old girl who was diagnosed with congenial lobar emphysema in the early period and who was followed with conservative treatment because of mild symptoms.

Keywords: child, congenital lobar emphysema, conservative treatment

\section{Giriş}

Konjenial lober amfizem (KLA), akciğerde bir lobun, birden fazla loba ait segmentin veya birden fazla bronşun intraluminer obstrüksiyon ile ileri derecede hiperinflasyona uğraması sonucu etkilenen lobun komşu akciğer dokusuna basısı ve akciğer herniasyonu ile karakterize bir anomalidir (1). Vakaların 1/3'ü doğumda, bunların çoğu da yaşamın ilk 6 ayında fark edilir. En sık sol üst lob ve daha az sıklıkla da sağ üst ve sağ orta lob etkilenir $(2,3)$. Hastalı̆̆n etiyolojisi tam olarak bilinmemesine rağmen alveollerde hasar oluşturan enfeksiyonlar, mukus tıkacı oluşumu sonrası etkilenen lob bronşunun obstrükte olması, yetersiz kıkırdak desteği nedeniyle bronşial kollapsın gelişmesi gibi çeşitli mekanizmalar ileri sürülmüştür $(4,5)$. Konjenial lober amfizem kliniği asemptomatikten, tekrarlayan takipne, tekrarlayan alt solunum yolu enfeksiyonları ve yenidoğan döneminde solunum yetmezliğine kadar çeşitlilik gösterir (6). Ağır semptomları olan hastalarda tutulan lobun cerrahi rezeksiyonu tüm dünyada kabul gören bir tedavi yöntemidir (7). Teknolojinin gelişmesi ile antenatal ultrasonografi ve radyolojik görüntüleme yöntemlerinin yaygın kullanımı ve daha kolay ulaşılabilir olması sonucu asemptomatik veya hafif semptomları olan hastalarda KLA'nın erken teşhisi mümkün olabilmektedir. Erken tanı konulabilen bu hastaların bir kısmında KLA'nın gerileyebildiği gösterilmiştir $(8,9)$. Bu gelişmeler 1şığında seçilmiş hastalar için konservatif yaklaşımlar da geliştirilmiştir (6). $\mathrm{Bu}$ yazıda erken dönemde konjenial lober amfizem tanısı konulan, hafif semptomları olması nedeniyle de konservatif tedavi yöntemleri ile izlenilen 4 aylık kız hasta sunulmaktadır.

\section{Olgu}

Dört aylık kız hasta, yaklaşık 10 gündür devam eden öksürük şikayeti ile dış merkezde antibiyoterapi başlanmış ve solunum sıkıntısının da başlaması sonrasında çekilen akciğer grafisinde sol üst lobda havalanma artışının görülmesi üzerine kliniğimize sevk edilmişti. Özgeçmişinde benzer hastalık veya solunum sıkıntısı öyküsü yoktu.

Yazışma Adresi: Aylin Kont Özhan, Adana Şehir Eğitim ve Araştırma Hastanesi, Çocuk Sağlı̆̆ı ve Hastalıkları Kliniği, Yüreğir/Adana

E-Posta: aylinkont@hotmail.com

Alınma tarihi: 04.09.2019 / Kabul tarihi: 05.10.2020 / Yayımlanma tarihi: 20.09.2021

Konjenital lober amfizem - Kont Özhan ve ark. 
Geldiğinde siyanozu olmayan hastanın takipnesi (solunum sayısı 55/ dakika), hafif interkostal, suprasternal çekilmeleri ve bazallerde sibilan ronküsleri mevcuttu. Laboratuvar incelemelerinde CRP negatif ve kan gazı normaldi. Bronkodilatatör tedavi verilen hastanın interkostal çekilmeri azaldı, dinleme bulguları geriledi. Akciğer grafisinde sol akciğer üst lobda belirgin havalanma artışı, mediasten yapılarında hafif sağa şift ve sağ akciğerde hafif volüm kaybı izlenmekteydi (Resim 1). Yine hastaya yapılan kontrastsız toraks bilgisayarlı tomografi (BT) incelemesinde akciğer ve koronal kesitlerde, sol akciğer üst lobda havalanma artışı, zayıflamış bronşlar da başlaması sonrasında çekilen akciğer grafisinde sol üst lobda havalanma artışının görülmesi üzerine kliniğimize sevk edilmişti. Özgeçmişinde benzer hastalık veya solunum sıkıntısı öyküsü yoktu. Geldiğinde siyanozu olmayan hastanın takipnesi (solunum sayısı 55/dakika), hafif interkostal, suprasternal çekilmeleri ve bazallerde sibilan ronküsleri mevcuttu. Laboratuvar incelemelerinde CRP negatif ve kan gazı normaldi. Bronkodilatatör tedavi verilen hastanın interkostal çekilmeri azaldı, dinleme bulguları geriledi. Akciğer grafisinde sol akciğer üst lobda belirgin havalanma artışı, mediasten yapılarında hafif sağa şift ve sağ akciğerde hafif volüm kaybı izlenmekteydi (Resim 1). Yine hastaya yapılan kontrastsız toraks bilgisayarlı tomografi (BT) incelemesinde akciğer ve koronal kesitlerde, sol akciğer üst lobda havalanma artışı, zayıflamış bronşlar ve üst mediasten yapılarında sağa sift izlenmekte olup radyolojik bulguları konjenital lober amfizemi destekler nitelikteydi (Resim 2). Eşlik edebilecek anomaliler açısından yapılan batın USG normaldi. Damarsal yapıları değerlendirmek için yapılan ekokardiyografide özellik yoktu. Çocuk cerrahisi bölümü ile konsülte edilen hastanın solunum sıkıntsının da gerilemesi üzerine konservatif izlenmesine karar verildi.

Resim 1: Akciğer grafisinde sol akciğer üst lobda belirgin havalanma artışı, mediasten yapılarında hafif sağa şift ve sağ akciğerde hafif volüm kayb1.

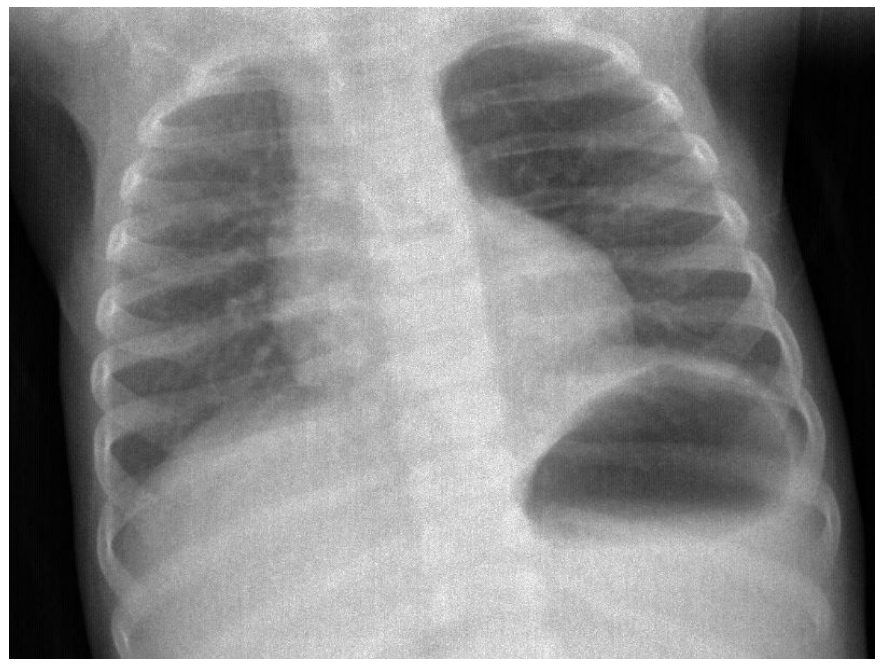

Resim 2: Toraks bilgisayarlı tomografi (BT) incelemesinde akciğer ve koronal kesitlerde, sol akciğer üst lobda havalanma artışı, zayıflamış bronşlar ve üst mediasten yapılarında sağa sift.

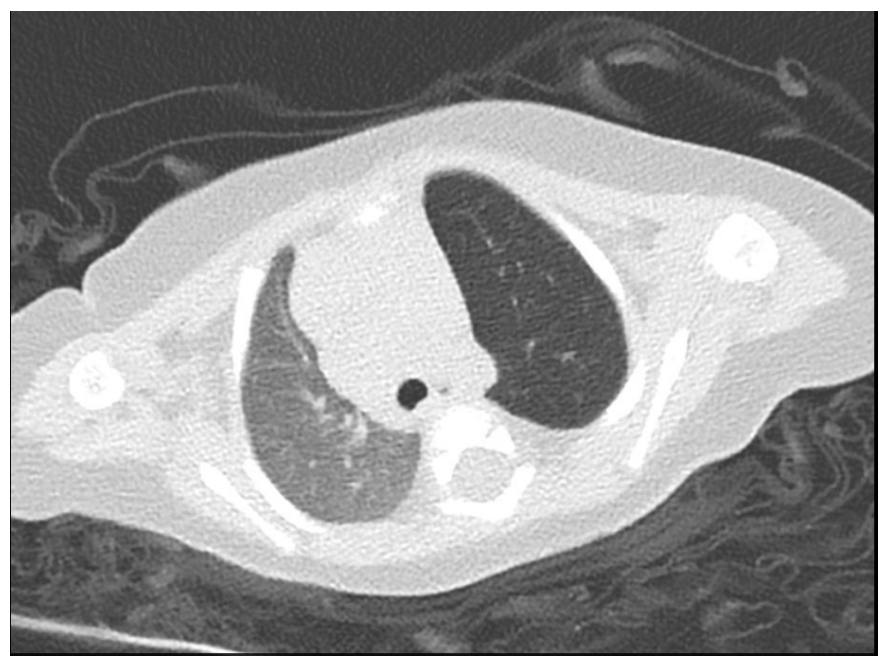

\section{Tartışma}

Konjenital lober amfizem, alt solunum yollarında hiperinflasyon ile karakterize nadir rastlanan akciğerin doğumsal bir anomalisidir. Konjenital lober amfizemin etiyolojisinde havayolu kıkırdak defekti, bronşiyal obstrüksiyon ve polialveolar lob formasyonu gibi nedenler düşünülse de, halen olguların yarısında etiyoloji bilinmemektedir $(10,11)$. Konjenital lober amfizem sıklığ 1/20000-30000 olarak bildirilmiştir. Erkek çocuklarındaki görülme sıklığı kız çocuklarından üç kat fazladır. Sol üst lob (\% 43) ve sağ orta lob (\% 32) en s1k etkilenen bölgelerdir (12). Olgumuzun cinsiyeti kız idi ve sol üst lob tutulumu vardi.

Konjenital lober amfizemli hastaların \%14'ünde kardiyovasküler anomaliler eşlik edebilir. Diyafragma hernisi, pektus ekskavatum, kondrodistrofi, yarık damak, pilor stenozu, omfalosel, renal agenezi ve renal kistler KLA ile birlikteliği tanımlanan diğer anomalilerdir (13). Olgumuzda KLA'ya eşlik eden herhangi bir ek anomali saptanmadi. Konjenital lober amfizemli hastalarda klinik seyir, hastalığın ortaya çıktığı yaşa, etkilenen loba veya etkilenen lobun normal loblara yaptığı basıya bağlı olarak değişebilir. Hastalarda yenidoğan döneminde ağır ve ilerleyici solunum sıkıntısı görülebileceği gibi, ilerleyen yaşlarda tekrarlayan alt solunum yolu enfeksiyonları, öksürük, hırıltılı solunum şikayetleri de görülebilir. Ayrıca dispne, takipne, vizing, taşikardi, beslenme güçlüğü ve siyanoz da diğer sık görülen belirtilerdir. Literatürde tansiyon pnömotoraks gelişmesi sonucu kardiak arrest ile başvuran olgular da bildirilmiştir (14). Olgumuzda solunum sıkıntısı hafif-orta düzeyde olup semptomatik tedavi ile de kliniğinde gerileme olmuştur.

Konjenital lober amfizem tanısında ilk basamak görüntüleme yöntemi olan akciğer grafisi başlangıçta yeterli bilgiyi sağlamakla birlikte kesin tanı için hastalarda bilgisayarlı toraks tomografisi çekilmesi gerekmektedir. Hastalarda hiperlusens alanların görülmesi, komşu lobların basıya uğraması, mediastende karşı tarafa itilme, aynı taraf diyafragmanın düzleşmesi ve bunlara ek olarak amfizematöz lobdaki venlerin incelmesinin görülmesi ile tanı konulur (15). Radyonüklid ventilasyon-perfüzyon sintigrafisi etkilenen lobda perfüzyon yokluğunu ve azalmış ventilasyonu göstermekte faydalıdır. Radyonüklid ventilasyon-perfüzyon sintigrafisi ile etkilenen lobun 
fonksiyonel olup olmadığı, basıya uğrayan akciğer lobunun normal fonksiyon gösterip göstermediği de anlaşlabilir $(16,17,18,19)$ Tüm hastalara bronkoskopi yapılmasının gerekliliği tartışmalıdır. Bronkoskopinin özellikle büyük çocuklarda ve konservatif tedaviyle takip edilmesi planlanan hastalarda mukus plakları, yabancı cisimler, anormal bronş yapılarının görülmesi ve hava yollarındaki dinamik değişikliklerin gösterilmesi açısından yapılabileceği düşünülse de ciddi solunum sıkıntısı olan olgularda bu işlemin solunum sıkıntısını daha da arttırabileceği bilinmektedir $(20,21)$. Hastamızın kliniğinin iyi olması ve konservatif tedaviye yanıt vermesi nedeniyle girişimsel bir işlem olan bronkoskopi tercih edilmemiş, teknik imkansızlıklar nedeniyle de ventilasyon-perfüzyon sintigrafisi yapılamamıştır.

Konjenital lober amfizem ayırıcı tanısında pnömatosel, pnömotoraks, diyafragma hernisi, karşı akciğerde hipoplazisi, konjenital adenoid malformasyon, postenfeksiyöz lober amfizem, yabancı cisim aspirasyonu, mukus tıkaçları ve endobronşiyal kitleler akılda tutulmalıdır (22,23). Ağır solunum sıkıntısı olan semptomatik hastalarda morbidite ve mortaliteyi önlemek amaciyla lobektomi önerilmektedir. Semptomları hafif seyreden hastalarda konservatif tedavi de tercih edilebilmektedir (24). Biz de olgumuzda hafif solunumsal semptomları olduğu için konservatif tedavi ile izlem kararı aldık.

\section{Sonuç}

Konjenital lober amfizem nadir görülen bir akciğer anomalisi olmasına rağmen, nedeni bilinmeyen solunum sıkıntısı olan hastalarda ayırıcı tanıda göz önünde bulundurulması gereken bir hastalıktır. Tanısı klinik ve görüntüleme yöntemleri ile birlikte konulur. Semptomları hafif olan olgular konservatif tedavi ile izlenirken, ağır solunum semptomu olan olguların lobektomi ile tedavisi iyi sonuçlar vermektedir.

\section{Kaynaklar}

1. Thakral CL, Maji DC, Sajwani MJ. Congenital lobar emphysema: experience with 21 cases. Pediatr Surg Int 2001;17:88-91.

2. Özçelik U, Göçmen A, Kiper N, Doğru D, Dilber E, Yalçın EG. Congenital lobar emphsema: evaluation and long-term follow up thirty cases at a single centre. Pediatr Pulmonol 2003;35:384-91

3. Celik M, Dostbil A, Aksoy M, et al. Anesthetic management in children with congenital lobar emphysema. Acta Chir Belg 2015;115:279-83.

4. Salzberg AM, Krummel TM. Congenital malformations of the lower respiratory tract. In: Chernick V, Kendig EL, eds. Kendig's disorders of the respiratory tract in children. 5th ed. Philadelphia: W.B. Saunders Co; 1990:227-67.

5. Reynolds M. Congenital lesions of the lung. In: Shields TW, Locicero III J, Reed CE, Feins RH, eds. General thoracic surgery, Vol 1, 7th ed. Philadelphia: Lippincott Williams\&Wilkins; 2009:1017-32.

6. Mei-Zahav M, Konen O, Manson D, Langer JC. Is congenital lobar emphysema a surgical disease? J Pediatr Surg 2006;4:1058-61

7. Karnak I, Senocak ME, Ciftci AO, Büyükpamukçu N. Congenital lobar emphysema: diagnostic and therapeutic considerations. J Pediatr Surg 1999;34:1347-51.

8. Blau H, Barak A, Karmazyn B, et al. Postnatal management of resolving fetal lung lesions. Pediatr 2002;109:105-8.

9. Quinton AE, Smoleniec JS. Congenital lobar emphysema-the disappearing chest mass: antenatal ultrasound appearance. Ultrasound Obstet Gynecol 2001;17:169-71.

10.Olutoye OO, Coleman BG, Hubbard AM, Adzick NS. Prenatal diagnosis an management of congenital lobar emphysema. J Pediatr Surg 2000; 35:792-5.
11. Berrocal T, Madrid C, Novo S, Gutiérrez J, Arjonilla A, Gómez-León N. Congenital anomalies of the tracheobronchial tree, lung, and mediastinum: embryology, radiology, and pathology. Radiographics 2004;24:e17.

12. Mei-Zahav M, Konen O, Manson D, Langer JC. Is congenital lobar emphysema a surgical disease? J Pediatr Surg 2006;41:1058-61.

13. Ozçelik U, Göçmen A, Kiper N, Doğru D, Dilber E, Yalçin EG. Congenital lobar emphysema: evaluation and long-term follow-up of thirty cases at a single center. Pediatr Pulmonol 2003;35:384-91.

14. Tempe DK, Virmani S, Javetkar S, Banerjee A, Puri SK, Datt V. Congenital lobar emphysema: pitfalls and management. Ann Card Anaesth 2010;13:53-8.

15. Williams HJ, Johnson KJ. Imaging of congenital cystic lung lesions. Paediatr Respir Rev 2002;3:120-7.

16. Mauney FM, Sabiston DC. The role of pulmonary scanning in the diagnosis of congenital lobar emphysema. Am Surg 1970;36:20-7.

17. Padilla L, Orzel JA, Kreins CM, Weiland FL. Congenital lobar emphysema: segmental lobar involvement demonstrated on ventilation and perfusion imaging. J Nucl Med 1985;26:1343-4

18. Oates E, Sarno RC. Solubilized xenon 133 lung scintigraphy. J Pediatr Surg $1988 ; 23: 1002-4$

19. Markowitz RI, Mercurio MR, Vahjen GA, Gross I, Touloukian RJ. Congenital lobar emphysema. The roles of CT and V/Q scan.Clin Pediatr (Phila) 1989;28:19-23.

20. Ulku R, Onat S, Ozçelik C. Congenital lobar emphysema: differential diagnosis and therapeutic approach. Pediatr Int 2008;50:658-61 .

21. Karnak I, Senocak ME, Ciftci AO, Büyükpamukçu N. Congenital lobar emphysema: diagnostic and therapeutic considerations. J Pediatr Surg 1999;34:1347-51.

22. Murray GF, Talbert JL, Haller JA. Obstructive lobar emphysema of the newborn infant. Documentation of the "mucus plug syndrome" with successful treatment by bronchotomy. J Thorac Cardiovas Surg 1967;53:886-90.

23. Cooney DR, Menke JA, Allen JE. "Acquired" lobar emphysema: a complication of respiratory distress in premature infants. J Pediatr Surg 1977;12:897-904.

24. Ulku R, Onat S, Ozçelik C. Congenital lobar emphysema: differential diagnosis and therapeutic approach. Pediatr Int 2008; 50:658-61. 